\title{
Detection of Malingering Using Wechsler Adult Intelligence Scale-IV for Psychiatric Patients
}

\author{
An Kook On ${ }^{1,2}$, Kyu-Sic Hwang ${ }^{1,2}$, Seung-Ho Jang ${ }^{1,2,3}$, Hye-Jin Lee ${ }^{4}$, Min-Jung Soh ${ }^{1,2}$, \\ Chan-Mo Yang ${ }^{2,5}$, and Sang-Yeol Lee $e^{1,2,3 凶}$ \\ ${ }^{1}$ Department of Psychiatry, Wonkwang University Hospital, Iksan, Republic of Korea \\ ${ }^{2}$ Korea Brain-Behavior Mental Health Institute, Iksan, Republic of Korea \\ ${ }^{3}$ Department of Psychiatry, School of Medicine, Wonkwang University, Iksan, Republic of Korea \\ ${ }^{4}$ Department of Public Health, Wonkwang University Graduate School, Iksan, Republic of Korea \\ ${ }^{5}$ Department of Psychiatry, Seoul National University Hospital, Seoul, Republic of Korea
}

\begin{abstract}
Objective Psychiatric patients sometimes show poor performance or exaggerated symptoms as malingering for secondary gain. The aim of this study was to introduce cut-off scores for detecting poor performance using Wechsler Adult Intelligence Scale (WAIS) in psychiatric patients.

Methods Participants were 261 in- and out-patients who visited psychiatry department. They were classified into 4 group- 1) military service, 2) traumatic brain injury (TBI), 3) psychosis, 4) neurosis. A Digit Span subtest (called as Reliable Digit Span, RDS) of WAIS was used to detect malingering. This study considered a score of $10 \%$ base rate as RDS cut-off score.

Results The RDS cut-off score was shown at 7 pts for military service group, at 3 pts for TBI group, at 6 pts for psychosis group, and at 6 pts for neurosis group.

Conclusion This study first introduced RDS cut-off scores for malingering psychiatric patients in South Korea. In clinical practice, clinicians may be able to utilize the RDS cut-off scores for malingering-suspected patients. In particular, for patients with military service issues, 7 or less pts of RDS can be used for detecting and inferring their malingering.

Psychiatry Investig 2020;17(6):526-532
\end{abstract}

Key Words Malingering, Performance validity, WAIS-IV, Reliable Digit Span, Military service.

\section{INTRODUCTION}

After examinees complete a psychological assessment in a psychiatric setting, clinicians judge whether the examinee is making reasonable efforts in performing the psychological test, is reporting exaggerated symptoms, or conversely, under-reporting their symptoms. Testifying the validity of the psychological assessment is very important for both the evaluators and for the clinicians who receive the report. ${ }^{1-3}$ Specifically, the examinee may show a poor effort in the psychological test by over- or under-reporting their symptoms for various reasons,

Received: December 29, 2019 Revised: February 20, 2020

Accepted: February 27, 2020

$\triangle$ Correspondence: Sang-Yeol Lee, MD, $\mathrm{PhD}$

Department of Psychiatry, School of Medicine, Wonkwang University, 895 Muwang-ro, Iksan 54538, Republic of Korea

Tel: +82-63-859-1044, Fax: +82-63-857-1043

E-mail: psysangyeol@hanmail.net

(a) This is an Open Access article distributed under the terms of the Creative Commons Attribution Non-Commercial License (https://creativecommons.org/licenses/bync/4.0) which permits unrestricted non-commercial use, distribution, and reproduction in any medium, provided the original work is properly cited. including legal issues, financial gain, stigmas, or refusal of treatment; clinicians must be aware of this to obtain valid data. ${ }^{1,4}$ However, it is not easy for the clinicians to determine whether the examinee has made best efforts in the psychological test based on performance-based measures, self-reported measures, and clinical judgments. Thus, ensuring the reliability of the psychological test is very difficult., ${ }^{5,6}$

Generally, self-reported measures have validity scales embedded in the tests which could help clinicians determine the over- or under-reporting of symptoms reported by examinees. The F scale in the Minnesota Multiphasic Personality Inventory-2 (MMPI-2), one of the most well-known self-reported measures, is a scale that can effectively detect examinees who exaggerate psychopathology in the tests. ${ }^{7-10}$ The L or K scale in the MMPI-2 can effectively detect under-reporting. ${ }^{11}$ In another self-reported measure known as the Personality Assessment Inventory (PAI), the negative impression (NIM) scale measures distorted responses to provide a negative impression, while positive impression (PIM) measures the attempts 
to impress to provide a positive impression. ${ }^{12}$

In contrast, performance-based measures often do not include the validity scales that are included in the self-reported measures. Determining validity in performance-based measures entirely depends on the examinee's performance efforts. In this case, it may be difficult to judge poor performance or malingering unless clinicians have an objective basis for judging the examinee's performance validity. The most commonly used performance-based measures in psychiatry can be intelligence tests, and the most recent Wechsler Adult Intelligence Scale-IV (WAIS-IV) is one of the most widely used adult intelligence tests. ${ }^{13,14}$ Similarly, it may be difficult for the clinician to judge whether or not proper efforts have been made by the examinee in WAIS-IV. In this study, the Korean-Wechsler Adult Intelligence Scale-IV (K-WAIS-IV) was used to verify the performance validity of examinees and to suggest the indicator of performance validity so that it can be easily utilized in actual psychiatric settings. ${ }^{15}$ First, a brief review of the tests that allow the clinician to determine the validity of performances or symptoms will be followed.

There are two main types of test that can identify poor performance and response bias. One is Symptom Validity Tests (SVTs) that can detect over- and under-reporting symptoms, and the other is Performance Validity Tests (PVTs) that can detect poor performance. ${ }^{16}$ PVTs detect poor performance and are mainly used in neuropsychological and intelligence tests. PVTs were initially used in forensic settings with a high rate of malingering patients, and were often helpful in determining malingering severity. ${ }^{17,18}$ Next, SVTs detect over-reporting or false reports of symptoms and can be used in self-reported measures or structured interviews. In typical self-reported measures such as MMPI-2, the clinician can detect falsified symptoms or over-reporting by examinees through the validity scales. ${ }^{19}$

PVTs can be categorized into two types. The embedded type that utilize a part or a subtest that belongs to an individual test. The stand-alone type is a completely individual test. Embedded types include the Digit Span of the Wechsler intelligence scales, ${ }^{20}$ the Rey-Osterrieth Complex Figure Test of the Rey Memory Test, ${ }^{21}$ and so forth. Stand-alone types include the California Verbal Learning Test, ${ }^{22}$ the Test of Memory Malingering, ${ }^{23}$ the Word Memory Test, ${ }^{24}$ and so forth. Particularly, embedded-type PVTs do not require additional time and costs, and they can be easily and quickly used in a clinical setting.

One of the embedded-type PVTs called the Reliable Digit Span (RDS) is a PVT that uses the Digit Span subtest score on the Wechsler Adult Intelligence Scale (WAIS). RDS is one of the most studied PVTs and is one of the most commonly used PVTs in various fields. ${ }^{18,25}$ Greiffenstein et al. ${ }^{20}$ first used the Digit Span subtest on the Wechsler adult intelligence scale to develop RDS. ${ }^{26}$ They considered the inconsistent memory test results in head trauma patients as a secondary gain..$^{27,28}$ Based on this, they derived RDS from the Wechsler intelligence scale. RDS is calculated by using the Longest Digit Span Forward (LDSF) and Longest Digit Span Backward (LDSB) on the WAIS. ${ }^{20}$

In previous studies, researchers attempted to find appropriate cut-off scores for RDS in various groups. Greiffenstein et al. ${ }^{20}$ regarded an RDS score of 7 pts as the appropriate cutoff score. ${ }^{20}$ A subsequent review study on patients with Traumatic Brain Injury (TBI), intellectual disabilities, adult Attention Deficit Hyperactivity Disorder (ADHD), and chronic pain found that an RDS score of 7 pts was the appropriate cut-off score for the group of TBI, adult ADHD, and chronic pain patients. However, the study found that an RDS score of 6 pts was the appropriate cut-off score for the groups with severe memory disorders, intellectual disabilities, borderline intelligence, and those whose mother tongue is not English. ${ }^{18}$ Another previous study with a psychosis group (consisting of patients with the schizophrenia spectrum disorders and other psychotic disorders) and a non-psychosis group (consisting of patients with major depressive disorder, generalized anxiety disorder, and post-traumatic stress disorder) found that an RDS score of 7 pts was a more appropriate cut-off score. ${ }^{29}$ In addition, previous studies on mixed clinical patients (depressive disorders, pain disorders, seizure disorders, and etc.) suggested that an RDS score of 6 pts was the appropriate cut-off score. ${ }^{30,31}$ In contrast, previous studies with persistent post-concussive patients, neurocognitive dysfunction patients, and university students showed that an RDS score of 7 pts was the appropriate cut-off score. . $^{32-34}$

Some studies have suggested an RDS score of 5 and 3 pts. One with cognitive impairment patients found that an RDS score of 5 pts was the appropriate cut-off score. ${ }^{35}$ The other one with participants with low IQs of 70 or below suggested that an RDS score of 3 pts was the appropriate cut-off score. ${ }^{36}$

Taken all together, the results of previous studies seem to consider RDS scores of 6 or 7 as the appropriate cut-off score. However, in the patient group with organic deficits such as TBIs or intellectual disabilities, RDS scores of 3 or 5 pts can be the appropriate cut-off score. Therefore, RDS cut-off scores are expected to differ from different patient groups. In addition, Lippa ${ }^{37}$ reported that few RDS studies have focused on non-English speakers, especially Asian patients. Therefore, the RDS cut-off score may be different from Asian patients than from English-speakers because of cultural differences.

Meanwhile, the studies on RDS have rarely studied in South Korea. The review article from Jeong and $\mathrm{Choi}^{38}$ briefly mentioned RDS as one of the WAIS-based indicators for detecting malingering. Similar to RDS, Moon and Hwang ${ }^{39}$ suggested the 
discriminant function formula using WAIS in order to detect malingering in patients with mild TBI. The formula included WAIS subtests such as Digit Span, Vocabulary, Visual Puzzles, and Coding subtests. Moreover, among the subtests included in the discriminant function formula, Moon and Hwang ${ }^{39}$ noted that the Digit Span subtest was the best discriminator for malingering. Moon and Hwang ${ }^{40}$ suggested the more studies on malingering in South Korea are needed and that fundamental epidemiologic studies including base rate by group should be preceded first.

The aim of this study is to suggest the cumulative frequency and base rate of RDS and to provide the RDS cut-off score for epidemiologic data and malingering detection in the psychiatric field. The base rate here refers to the prevalence or the cumulative frequency of the observed score. A low RDS base rate refers to a low prevalence or cumulative frequency of the RDS score. Typically, being statistically significant based on $p$ values and having a low prevalence as per the base rate are independent of each other. ${ }^{13}$ A specific score can be low with statistical significance, but the prevalence based on the base rate or the cumulative frequency can be quite common. ${ }^{13} \mathrm{~A}$ previous study examining the RDS base rate showed that an RDS score corresponding to $10 \%$ of the base rate can be regarded as the cut-off score. ${ }^{6,41}$ Therefore, an RDS score corresponding to $10 \%$ of the base rate was considered as cut-off score in this study.

\section{METHODS}

\section{Participants}

Participants included in- and out- patients who visited the psychiatry department from December 2016 to November 2018. They were divided into 4-group by psychiatrists based on the Diagnostic and Statistical Manual of Mental Disorder Fifth Edition (DSM-5): 1) patients visiting for military service issues (military service group, $\mathrm{n}=61$ ); 2) patients visiting for disability and compensation assessment after being diagnosed with major or mild neurocognitive disorders due to TBIs (TBI group, $\mathrm{n}=57$ ); 3) patients with psychosis including the schizophrenia spectrum and other psychotic disorders and bipolar disorder (psychosis group, $\mathrm{n}=47$ ); 4) patients with depressive and anxiety disorders (neurosis group, $n=96$ ). The study was conducted after obtaining the approval of the Institutional Review Board of the Wonkwang University Hospital (IRB No. WKUH 2019-07-015).

\section{Measures}

\section{Reliable Digit Span of K-WAIS-IV}

The Korean version of WAIS-IV (K-WAIS-IV) by Hwang et al. ${ }^{15}$ was used in this study. K-WAIS-IV consists of ten core subtests and five supplemental subtests. The Digit Span subtest from ten core subtests was used to calculate RDS from KWAIS-IV. The Digit Span subtest is a core subtest of the Working Memory Index (WMI) and consists of the tasks Digit Span Forward (DSF), Digit Span Backward (DSB), and Digit Span Sequencing (DSS). These three tasks each run the same Digit Span of numbers twice with increasing difficulty as the task progresses due to the increasing Digit Span of the numbers. In the Digit Span subtest, the clinician can calculate the raw scores and process scores for DSF, DSB, and DSS.

RDS can be calculated as follows. Among the process scores in the Digit Span subtest, RDS is calculated by adding the scores from the Longest Digit Span Forward (LDSF) and the Longest Digit Span Backward (LDSB). However, when calculating RDS, it is calculated with the longest Digit Span score where two questions are answered correctly in the trial with the same Digit Span. Caution is required as it is different from the method of calculating the longest Digit Span score that is

Table 1. Example of Reliable Digit Span calculation

\begin{tabular}{|c|c|c|c|c|c|c|c|c|c|}
\hline \multicolumn{5}{|c|}{ Digit Span forward } & \multicolumn{5}{|c|}{ Digit Span backward } \\
\hline Trial & Span & Presented & Response & Score & Trial & Span & Presented & Response & Score \\
\hline \multirow[t]{2}{*}{1} & 2 & 12 & 12 & 1 & 1 & $2^{*}$ & 23 & 32 & 1 \\
\hline & & 23 & 23 & 1 & & & 34 & 43 & 1 \\
\hline \multirow[t]{2}{*}{2} & $3^{*}$ & 123 & 123 & 1 & 2 & 3 & 234 & 213 & 0 \\
\hline & & 234 & 234 & 1 & & & 345 & 534 & 0 \\
\hline \multirow[t]{2}{*}{3} & 4 & 1234 & 1234 & 1 & 3 & 4 & 1234 & - & - \\
\hline & & 2345 & 1244 & 0 & & & 2345 & - & - \\
\hline \multirow[t]{2}{*}{4} & 5 & 12345 & 12235 & 0 & 4 & 5 & 12345 & - & - \\
\hline & & 23456 & 24545 & 0 & & & 23456 & - & - \\
\hline
\end{tabular}

Reliable Digit Span score $=5$ pts

*Reliable Digit Span score: Longest Digit Span forward score+Longest Digit Span backward score (ex. 3 span +2 span $\rightarrow$ Reliable Digit Span score 5 pts.), Longest Digit Span score where two questions must be answered correctly in the trial with the same Digit Span 
required in the K-WAIS-IV administration and scoring manual. The illustrative example is shown at Table 1.

\section{Data analysis}

Frequency and descriptive analysis were conducted to examine the demographic characteristics. Age and level of education were presented as average and standard deviations, while gender was presented as the number of cases and a percentage. The indexes and the scaled scores by group were presented as average and standard deviations through frequency analysis. Next, frequency analysis was conducted in order to examine the cumulative percentage and base rate of RDS, and the results were presented as a cumulative frequency and base rate (cumulative percentage). According to a previous study, ${ }^{6,41}$ an RDS score corresponding to $10 \%$ of the base rate through frequency analysis was considered as the cut-off score in this study. In order to examine the difference in RDS scores among the groups, ANOVA was conducted. Moreover, $\eta^{2}$, which represents the effect size in ANOVA, was calculated; $\eta^{2}$ values of 0.01 to 0.06 represent a "small effect," 0.06 to 0.14 represent a "medium effect," and 0.14 and above represent a "large effect." 42 This study used SPSS 21.00 (IBM Corp., Armonk, NY, USA) for statistical analysis.

\section{RESULTS}

\section{Demographic data}

The demographic data of this study are as follows (Table 2). The average age by group was 21.22, 57.05, 32.10, and 34.29 years old for the military service, TBI, psychosis, and neurosis, respectively. Next, the number of cases for each gender showed 61 males in the military service group which corresponded to $100 \%$. TBI group showed 48 males, corresponding to $84.21 \%$, while the number of females was 9, corresponding to $15.79 \%$. In the psychosis group, there were 21 females corresponding to $44.68 \%$, and 26 females corresponding to $55.32 \%$. The neurosis group had 36 females corresponding to $37.50 \%$, and 60 females corresponding to $62.50 \%$.

\section{K-WAIS-IV scores by group}

The FSIQ score of the military service group was 83.21 pts.
The FSIQ scores of the TBI, psychosis, and neurosis groups were 67.96 pts, 77.38 pts, and 83.51 pts, respectively. The indexes of K-WAIS-IV and the scaled scores of subtest by group are presented in Table 3.

\section{Base rate of RDS}

The RDS score corresponding to $10 \%$ of the base rate for each group was confirmed (Table 4). It was 7 pts for the military service group, 6 pts for the neurosis and psychosis groups, and 3 pts for the TBI group.

Table 3. Mean and standard deviation of K-WAIS-IV FSIQ, index, subtest scaled scores by group

\begin{tabular}{lcccc}
\hline Index/ & $\begin{array}{c}\text { Military } \\
\text { service } \\
\text { subtest }\end{array}$ & $\begin{array}{c}\text { TBI } \\
(\mathrm{N}=61) \\
\text { Mean } \pm \text { SD }\end{array}$ & $\begin{array}{c}\text { Mean } \pm \text { SD } \\
\text { Psychosis } \\
(\mathrm{N}=47)\end{array}$ & $\begin{array}{c}\text { Mean } \pm \text { SD } \\
(\mathrm{N}=96) \\
\text { Mean } \pm \text { SD }\end{array}$ \\
\hline VCI & $89.64 \pm 13.71$ & $78.84 \pm 14.85$ & $86.43 \pm 19.33$ & $91.34 \pm 15.55$ \\
SI & $8.16 \pm 3.01$ & $5.91 \pm 3.14$ & $7.49 \pm 3.58$ & $8.73 \pm 3.47$ \\
VC & $7.56 \pm 3.20$ & $5.81 \pm 2.42$ & $7.13 \pm 3.92$ & $8.33 \pm 3.07$ \\
IN & $8.54 \pm 2.38$ & $6.89 \pm 3.12$ & $7.98 \pm 3.18$ & $8.1 \pm 2.77$ \\
PRI & $88.33 \pm 18.65$ & $73.25 \pm 16.09$ & $82.96 \pm 18.99$ & $85.69 \pm 16.62$ \\
BD & $7.44 \pm 4.03$ & $4.98 \pm 2.87$ & $6.98 \pm 3.50$ & $7.06 \pm 3.30$ \\
MR & $8.34 \pm 2.91$ & $5.84 \pm 3.23$ & $7.79 \pm 3.51$ & $7.9 \pm 2.94$ \\
VP & $8.38 \pm 3.09$ & $5.95 \pm 2.96$ & $6.81 \pm 3.17$ & $7.83 \pm 2.93$ \\
WMI & $90.89 \pm 18.02$ & $76.07 \pm 16.05$ & $81.09 \pm 18.74$ & $87.98 \pm 16.36$ \\
DS & $8.59 \pm 3.55$ & $5.21 \pm 3.26$ & $7.04 \pm 3.74$ & $8.14 \pm 3.20$ \\
AR & $8.02 \pm 3.23$ & $6.19 \pm 2.65$ & $6.09 \pm 3.33$ & $7.34 \pm 3.12$ \\
PSI & $80.11 \pm 15.24$ & $69.72 \pm 14.89$ & $77.19 \pm 21.33$ & $85.21 \pm 17.49$ \\
SS & $6.7 \pm 3.33$ & $4.3 \pm 2.57$ & $5.98 \pm 3.82$ & $7.09 \pm 3.42$ \\
CD & $5.34 \pm 2.54$ & $4.16 \pm 2.77$ & $5.32 \pm 4.20$ & $6.91 \pm 3.40$ \\
FSIQ & $83.21 \pm 16.26$ & $67.96 \pm 15.58$ & $77.38 \pm 20.90$ & $83.51 \pm 16.69$ \\
\hline K-WAIS-IV: Koren & & &
\end{tabular}

K-WAIS-IV: Korean Wechsler Adult Intelligence Scale-IV, FSIQ: full scale intelligence quotient, VCI: verbal comprehension index, PRI: perceptual reasoning index, WMI: working memory index, PSI: processing speed index, SI: similarities, VC: vocabulary, IN: information, BD: block design, MR: matrix reasoning, VP: visual puzzles, DS: Digit Span, AR: arithmetic, SS: symbol search, CD: coding, military service: group of patients visiting for a military service issues, TBI: traumatic brain injury

Table 2. Demographic characteristics by group

\begin{tabular}{lcccc}
\hline & Military service $(\mathrm{N}=61)$ & TBI $(\mathrm{N}=57)$ & Psychosis $(\mathrm{N}=47)$ & Neurosis $(\mathrm{N}=96)$ \\
\hline Age (year), mean $\pm \mathrm{SD}$ & $21.22 \pm 7.2$ & $57.05 \pm 13.24$ & $32.10 \pm 10.84$ & $34.29 \pm 16.85$ \\
Sex, $\mathrm{N}(\%)$ & & & \\
$\quad$ Male & $61(100)$ & $48(84.21)$ & $21(44.68)$ & $36(37.50)$ \\
$\quad$ Female & $0(0)$ & $9(15.79)$ & $26(55.32)$ & $60(62.50)$ \\
Education (year), mean $\pm \mathrm{SD}$ & $12.59 \pm 1.33$ & $10.51 \pm 7.11$ & $13.02 \pm 2.39$ & $11.89 \pm 3.22$ \\
\hline
\end{tabular}

Military service: group of patients visiting for military service issues. TBI: traumatic brain injury 
Table 4. Base rate of Reliable Digit Span score for each group

\begin{tabular}{|c|c|c|c|c|c|c|c|c|}
\hline \multirow{2}{*}{$\begin{array}{l}\text { RDS } \\
\text { score }\end{array}$} & \multicolumn{2}{|c|}{ Military service $(\mathrm{N}=61)$} & \multicolumn{2}{|c|}{ TBI $(\mathrm{N}=57)$} & \multicolumn{2}{|c|}{ Psychosis $(\mathrm{N}=47)$} & \multicolumn{2}{|c|}{ Neurosis $(\mathrm{N}=96)$} \\
\hline & $\begin{array}{c}\text { Cumulative } \\
\text { frequency }\end{array}$ & Base rate & $\begin{array}{l}\text { Cumulative } \\
\text { frequency }\end{array}$ & Base rate & $\begin{array}{l}\text { Cumulative } \\
\text { frequency }\end{array}$ & Base rate & $\begin{array}{c}\text { Cumulative } \\
\text { frequency }\end{array}$ & Base rate \\
\hline 0 & 0 & 0.00 & 4 & 7.02 & 0 & 0.00 & 0 & 0.00 \\
\hline$\leq 1$ & 0 & 0.00 & 4 & 7.02 & 0 & 0.00 & 0 & 0.00 \\
\hline$\leq 2$ & 0 & 0.00 & 4 & 7.02 & 1 & 2.13 & 0 & 0.00 \\
\hline$\leq 3$ & 0 & 0.00 & 7 & 12.28 & 1 & 2.13 & 1 & 1.04 \\
\hline$\leq 4$ & 0 & 0.00 & 13 & 22.81 & 1 & 2.13 & 2 & 2.08 \\
\hline$\leq 5$ & 0 & 0.00 & 26 & 45.61 & 2 & 4.26 & 7 & 7.29 \\
\hline$\leq 6$ & 3 & 4.92 & 34 & 59.65 & 6 & 12.77 & 11 & 11.46 \\
\hline$\leq 7$ & 6 & 9.84 & 43 & 75.44 & 13 & 27.66 & 20 & 20.83 \\
\hline$\leq 8$ & 14 & 22.95 & 48 & 84.21 & 19 & 40.43 & 31 & 32.29 \\
\hline$\leq 9$ & 21 & 34.43 & 53 & 92.98 & 26 & 55.32 & 48 & 50.00 \\
\hline$\leq 10$ & 29 & 47.54 & 54 & 94.74 & 38 & 80.85 & 61 & 63.54 \\
\hline$\leq 11-18$ & 61 & 100.00 & 57 & 100.00 & 47 & 100.00 & 96 & 100.00 \\
\hline
\end{tabular}

Military service: group of patients visiting for a military service issues. TBI: traumatic brain injury

Table 5. Testifying mean difference of RDS scores by group

\begin{tabular}{|c|c|c|c|c|c|c|c|}
\hline & \multicolumn{4}{|c|}{ Group, mean \pm SD } & \multicolumn{3}{|c|}{ Statistic } \\
\hline & Military servicea $(\mathrm{N}=61)$ & TBIb $(\mathrm{N}=57)$ & Psychosisc $(\mathrm{N}=47)$ & Neurosisd $(\mathrm{N}=96)$ & $\mathrm{F}$ & $\eta^{2}$ & Post-hoc (scheffe) \\
\hline RDS & $10.65 \pm 2.58$ & $5.92 \pm 2.61$ & $9.02 \pm 2.52$ & $9.59 \pm 2.63$ & $36.35^{* * *}$ & 0.30 & $a>c>b, d>b$ \\
\hline
\end{tabular}

\section{Difference between groups for RDS scores}

Table 5 shows the difference in RDS scores among the military service, TBI, neurosis, and psychosis groups. The average $\mathrm{RDS}$ was $10.65 \mathrm{pts}(\mathrm{SD}=2.58 \mathrm{pts}$ ) for the military service group, $5.92 \mathrm{pts}$ ( $\mathrm{SD}=2.61 \mathrm{pts}$ ) for the TBI group, $9.02 \mathrm{pts}(\mathrm{SD}=2.52 \mathrm{pts}$ ) for the psychosis group, and $9.59 \mathrm{pts}$ ( $\mathrm{SD}=2.63 \mathrm{pts}$ ) for the neurosis group. In the test for differences in the averages, a significant difference among the groups was observed $(\mathrm{F}=36.35$, $\mathrm{p}<0.001$ ). In addition, $\eta^{2}$ was found to be 0.30 , corresponding to a "large effect." When the difference among the groups was examined in detail using post-hoc analysis, the RDS score for the TBI group was significantly lower than that of other groups. The RDS score for the military service group was significantly higher than that of the psychosis group. The RDS score for the neurosis group did not show a significant difference from that of the military service or the psychosis group but was still significantly higher than that of the TBI group.

\section{DISCUSSION}

RDS in WAIS is one of the representative PVTs that can assess poor performance by examinees. This study attempted to provide fundamental epidemiological data for the clinical field by calculating the cumulative frequency and base rate of RDS using K-WAIS-IV. Thus, the present study analyzed the
RDS base rate by group (military service, TBI, psychosis, and neurosis) and introduced the RDS cut-off score corresponding to $10 \%$ of the base rate. The study also testified the difference in RDS scores among the groups.

As with previous studies, this study regarded $10 \%$ of the base rate as cut-off. ${ }^{6,41}$ The RDS scores corresponding to $10 \%$ of the base rate for each group were $7 \mathrm{pts}$ for the military service group, 3 pts for the TBI group, psychosis groups, and 6 pts for the neurosis. The each RDS scores can be regarded as the cut-off scores for the each group. ${ }^{6,41}$

The results of this study were compared with that of previous studies that suggested RDS cut-off scores by receiver operating characteristic analysis (ROC). The previous studies on persistent post-concussive patients, neurocognitive dysfunction patients, and university students suggested 7pts of RDS cut-off score, which is the same cut-off score for the military service group of this study. ${ }^{32-34}$ Furthermore, 6 pts of RDS cutoff score for the neurosis and psychosis groups in this study was coincided with the results of the previous study on mixed clinical patients and chronic pain patients. ${ }^{30,31}$

On the other hand, for the TBI group in this study, the RDS cut-off score was 3 pts, which was coincided with the results of the previous study on patients with low IQs of below 70. ${ }^{36}$ In the present study, the RDS score of the TBI group was relatively lower than that of the military service, psychosis, and 
neurosis groups. The reason could be the effects of brain damage so that the participants with TBI had more difficulties with performing cognitive tasks than the military service group. ${ }^{36}$

In summary, the RDS cut-off score was 7, 6, and 3 pts for the military service, neurosis and psychosis, and TBI groups, respectively. If the RDS cut-off scores or lower scores were shown in practice, the clinician might suspect intentional poor performance or malingering attitude. Practically, if the examinees with the military service issues show RDS 7 or less pts, high chance of malingering could be suspected.

However, the clinician should not utilize the RDS cut-off score alone to evaluate malingering. In order to detect malingering or intentional poor performance, a multidimensional approach is necessarily required. ${ }^{34,43,44}$ As such, using the discriminant function formula introduced in South Korea by Moon and Hwang ${ }^{39}$ with the RDS cut-off score would increase the validity of the detection of malingering. However, the formula is recommended to be used with the mild TBI group because the discriminant function formula was originally designed to distinguish the mild TBI group from the malingering group. In addition, in order to detect intentional poor performance and malingering, clinicians may additionally conduct PVTs, such as the California Verbal Learning Test, the ReyOsterrieth Complex Figure Test, the Test of Memory Malingering, and the Word Memory Test. In addition to the test data, the process that integrates all the data including the examinee's personal, medical, and psychiatric history data is essential for the detection of malingering.

The significance of this study is as follows. Few studies on PVTs in South Korea were conducted, and this study first introduced PVTs using K-WAIS-IV RDS and suggested RDS cut-off scores by group. The K-WAIS-IV is the most widely used intelligence test in South Korea and is routinely administered in psychiatric settings. RDS can be easily used to examine performance validity using WAIS without any additional tests, which is very time- and cost-effective. Moreover, calculating RDS is very simple, and even clinicians can check for poor performance in the middle of the testing. The previous studies in South Korea have not shown a fundamental epidemiological data about RDS. ${ }^{40}$ This study could be the basis for future performance validity studies.

The limitations of this study and future research directions are as follows. This study introduced RDS cut-off scores using $10 \%$ of the base rate, not using ROC analysis. The replication studies showing RDS cut-off scores through ROC analysis will increase the statistical validity. Furthermore, RDS research needs to be conducted with a variety of groups. As with previous studies, the studies to apply and examine RDS to various subject groups such as those with intellectual disabilities, patients with dementia, and chronic pain patients are needed in
South Korea. ${ }^{18}$ Finally, no stand-alone-type PVTs such as the Test of Memory Malingering ${ }^{23}$ and the Word Memory Test ${ }^{24}$ are standardized in South Korea. The Korean version of standardized stand-alone-type PVTs will be able to increase the reliability and validity of detecting malingering with embedded-type PVTs together.

\section{Acknowledgments}

This study was supported by Wonkwang University in 2020.

\section{Conflicts of Interest}

The authors have no potential conflicts of interest to disclose.

\section{Author Contributions}

Conceptualization: Kyu-Sic Hwang. Data curation: Seung-Ho Jang. Formal analysis: Min-Jung Soh. Investigation: An Kook On. Methodology: Kyu-Sic Hwang. Project administration: Sang-Yeol Lee. Resources: An Kook On. Supervision: Sang-Yeol Lee. Validation: Kyu-Sic Hwang. Visualization: Chan-Mo Yang. Writing_original draft: An Kook On. Writingreview \& editing: Hye-Jin Lee, Sang-Yeol Lee.

\section{ORCID iDs}

An Kook On http://orcid.org/0000-0002-0171-4844 Kyu-Sic Hwang $\quad$ http://orcid.org/0000-0002-8997-8720

Seung-Ho Jang http://orcid.org/0000-0002-3479-0552

Hye-Jin Lee http://orcid.org/0000-0002-1039-9196

Min-Jung Soh http://orcid.org/0000-0003-1033-9449

Chan-Mo Yang http://orcid.org/0000-0002-4959-7595

Sang-Yeol Lee http://orcid.org/0000-0003-1828-9992

\section{REFERENCES}

1. Bush SS, Ruff RM, Tröster AI, Barth JT, Koffler SP, Pliskin NH, et al. Symptom validity assessment: Practice issues and medical necessity NAN Policy \& Planning Committee. Arch Clin Neuropsychol 2005; 20:419-426.

2. Heilbronner RL, Sweet JJ, Morgan JE, Larrabee GJ, Millis SR. American Academy of Clinical Neuropsychology Consensus Conference Statement on the neuropsychological assessment of effort, response bias, and malingering. Clin Neuropsychol 2009;23:1093-1129.

3. McCrea M, Pliskin N, Barth J, Cox D, Fink J, French L, et al. Official position of the military TBI task force on the role of neuropsychology and rehabilitation psychology in the evaluation, management, and research of military veterans with traumatic brain injury. Clin Neuropsychol 2008;22:10-26.

4. Mittenberg W, Patton C, Canyock EM, Condit DC. Base rates of malingering and symptom exeggeration. J Clin Exp Neuropsychol 2002; 24:1094-1102.

5. Heaton RK, Smith HH, Lehman RA, Vogt AT. Prospects for faking believable deficits on neuropsychological testing. J Consult Clin Psychol 1978;46:892-900.

6. Kaufman A, Lichtenberger E. Essentials of WAIS-IV Assessment. New York: John Wiley; 2009.

7. Baer RA, Kroll LS, Rinaldo J, Ballenger J. Detecting and discriminating between random responding and overreporting on the MMPI-A. J Pers Assess 1999;72:308-320.

8. Bagby RM, Buis T, Nicholson RA. Relative effectiveness of the standard validity scales in detecting fake-bad and fake-good responding: replication and extension. Psychol Assess 1995;7:84-92.

9. Iverson GL, Franzen MD, Hammond JA. Examination of inmates' ability to malinger on the MMPI-2. Psychol Assess 1995;7:118-121.

10. Meyer GJ, Archer RP. The hard science of Rorschach research: What 
do we know and where do we go? Psychol Assess 2001;13:486-502.

11. Bagby RM, Rogers R, Buis T, Nicholson RA, Cameron SL, Rector NA, et al. Detecting feigned depression and schizophrenia on the MMPI-2. J Pers Assess 1997;68:650-664.

12. Morey LC. The Personality Assessment Inventory. In: Archer RP, Smith SR, Editors. Personality Assessment, 2nd Ed. New York, NY: Routledge/Taylor \& Francis Group, 2014, p.181-228.

13. Wechsler D. Wechsler Adult Intelligence Scale: WAIS-IV; Technical and Interpretive Manual. San Antonio, Tex: Pearson; 2008.

14. Guilmette TJ, Faust D, Hart K, Arkes HR. A national survey of psychologists who offer neuropsychological services. Arch Clin Neuropsychol 1990;5:373-392.

15. Hwang ST, Kim JH, Park KB, Choi JY, Hong SH. Korean Wechsler Adult Intelligence Scale-IV. Daegu: Korea Psychology Co., LTD; 2012.

16. Larrabee GJ. Performance validity and symptom validity in neuropsychological assessment. J Int Neuropsychol Soc 2012;18:625-630.

17. Larrabee GJ. Detection of malingering using atypical performance patterns on standard neuropsychological tests. Clin Neuropsychol 2003; 17:410-425.

18. Schroeder RW, Twumasi-Ankrah P, Baade LE, Marshall PS. Reliable Digit Span: a systematic review and cross-validation study. Assessment 2012;19:21-30.

19. Greene RL. The MMPI-2: An Interpretive Manual. Boston: Allyn \& Bacon; 2000.

20. Greiffenstein MF, Baker WJ, Gola T. Validation of malingered amnesia measures with a large clinical sample. Psychol Assess 1994;6:218-224.

21. Lu PH, Boone KB, Cozolino L, Mitchell C. Effectiveness of the ReyOsterrieth Complex Figure Test and the Meyers and Meyers recognition trial in the detection of suspect effort. Clin Neuropsychol 2003; 17:426-440.

22. Delis DC, Kramer JH, Kaplan E, Thompkins BA. CVLT: California Verbal Learning Test-Adult Version: Manual. San Antonio, Tex: Psychological Corporation; 1987.

23. Tombaugh TN. Test of Memory Malingering. Toronto: Multi Health System; 1996.

24. Green P, Allen L, Astner K. Manual for Computerised Word Memory Test. Durham, NC: CogniSyst.; 1996.

25. Boone KB. Assessment of Feigned Cognitive Impairment: A Neuropsychological Perspective. New York: Guilford Press; 2007.

26. Wechsler D. The psychometric tradition: developing the Wechsler Adult Intelligence Scale. Contemp Educ Psychol 1981;6:82-85.

27. Millis SR. The Recognition Memory Test in the detection of malingered and exaggerated memory deficits. Clin Neuropsychol 1992;6:406-414.

28. Binder LM, Willis SC. Assesment of motivation after financially compensable minor head trauma. J Consult Clin Psychol 1991;3:175-181.

29. Schroeder RW, Marshall PS. Evaluation of the appropriateness of multiple symptom validity indices in psychotic and non-psychotic psychi- atric populations. Clin Neuropsychol 2011;25:437-453.

30. Babikian T, Boone KB, Lu P, Arnold G. Sensitivity and specificity of various digit span scores in the detection of suspect effort. Clin Neuropsychol 2006;20:145-159.

31. Greve KW, Bianchini KJ, Etherton JL, Meyers JE, Curtis KL, Ord JS. The reliable digit span test in chronic pain: classification accuracy in detecting malingered pain-related disability. Clin Neuropsychol 2010; 24:137-152.

32. Greiffenstein MF, Gola T, Baker WJ. MMPI-2 validity scales versus domain specific measures in detection of factitious traumatic brain injury. Clin Neuropsychol 1995;9:230-240.

33. Heinly MT, Greve KW, Bianchini KJ, Love JM, Brennan A. WAIS digit span-based indicators of malingered neurocognitive dysfunction: classification accuracy in traumatic brain injury. Assessment 2005;12:429444.

34. Schwarz LR, Gfeller JD, Oliveri MV. Detecting feigned impairment with the digit span and vocabulary subtests of the Wechsler Adult Intelligence Scale-third edition. Clin Neuropsychol 2006;20:741-753.

35. Webber TA, Soble JR. Utility of various WAIS-IV digit span indices for identifying noncredible performance validity among cognitively impaired and unimpaired examinees. Clin Neuropsychol 2018;32:657670.

36. Dean AC, Victor TL, Boone KB, Arnold G. The relationship of IQ to effort test performance. Clin Neuropsychol 2008;22:705-722.

37. Lippa SM. Performance validity testing in neuropsychology: a clinical guide, critical review, and update on a rapidly evolving literature. Clin Neuropsychol 2018;32:391-421.

38. Jeong NR, Choi S. The psychological review of detecting for malingering in clinical setting. Clin Psychol Kor Res Pract 2016;2:115-144.

39. Moon MJ, Hwang ST. Construction of a malingering discrimination indicator on K-WAIS-IV using discriminant function. Kor J Clin Psychol 2015;34:1039-1058.

40. Moon MJ, Hwang ST. A Review of studies for malingering discrimination index of malingered neurocognitive dysfunction. Kor J Psychol 2017;36:39-59.

41. Zenisek R, Millis SR, Banks SJ, Miller JB. Prevalence of below-criterion Reliable Digit Span scores in a clinical sample of older adults. Arch Clin Neuropsychol 2016;31:426-433.

42. Cohen J. Statistical Power Analysis for the Behavioral Sciences (2nd ed.). Hillsdale, NJ: Lawrence Erlbaum; 1988.

43. Nies KJ, Sweet JJ. Neuropsychological assessment and malingering: a critical review of past and present strategies. Arch Clin Neuropsychol 1994;9:501-552.

44. Powell MR, Gfeller JD, Hendricks BL, Sharland M. Detecting symptom- and test-coached simulators with the test of memory malingering. Arch Clin Neuropsychol 2004;19:693-702. 